\title{
UMA ANÁLISE SOBRE A INSERÇÃO PROFISSIONAL DE ESTUDANTES DE
}

\section{ADMINISTRAÇÃO NO BRASIL ${ }^{\mathrm{I}}$}

\section{SIDINEI ROCHA-DE-OLIVEIRA}

Doutor em Administração pelo Programa de Pós-Graduação em Administração da Universidade Federal do Rio Grande do Sul (UFRGS). Professor do Departamento de Ciências Administrativas da

Universidade Federal do Rio Grande do Sul (UFRGS).

Rua Washington Luis, 855, Centro, Porto Alegre - RS - Brasil - CEP 90010-460

E-mail: sroliveira@ea.ufrgs

\section{VALMIRIA CAROLINA PICCININI}

Doutora em Economia do Trabalho e da Produção pelo Institut d'Administration

$d^{\prime}$ Entreprises da Université Pierre Mendès (França).

Professora do Departamento de Ciências Administrativas da

Universidade Federal do Rio Grande do Sul (UFRGS).

Rua Washington Luis, 855, Centro, Porto Alegre - RS - Brasil - CEP 90010-460

E-mail:vpiccinini@ea.ufrgs.br

Agradecemos, in memorian, ao professor Didier Retour (IAE-Grenoble) pela preciosa contribuição no processo de produção deste artigo.

Este artigo pode ser copiado, distribuído, exibido, transmitido ou adaptado desde que citados, de forma clara e explícita, o nome da revista, a edição, o ano e as páginas nas quais o artigo foi publicado originalmente, mas sem sugerir que a RAM endosse a reutilização do artigo. Esse termo de licenciamento deve ser explicitado para os casos de reutilização ou distribuição para terceiros. Não é permitido o uso para fins comerciais. 


\section{RESUMO}

Atualmente os estágios representam uma forma de "inserção profissional organizada", estruturada na convergência dos sistemas educativo e produtivo, em que a escola/universidade já incorpora à formação aspectos de aprendizado prático, preparando a socialização para o trabalho. Para compreender como essas transformações têm se refletido no processo de ingresso no mundo do trabalho, este estudo tem por objetivo analisar a inserção profissional dos estudantes de Administração a partir da experiência de estágio em Porto Alegre e região metropolitana. A pesquisa seguiu uma orientação construtivista. Foram entrevistados 32 estudantes dos cursos de graduação em Administração que relataram suas experiências de estágio, apontando suas implicações para a inserção profissional e suas expectativas de carreira futura. Na análise, nota-se que, apesar do caráter de formação, o estágio nem sempre representa a etapa inicial do processo de inserção profissional, pois, pelas entrevistas, verifica-se que a primeira experiência profissional dos estudantes nem sempre está relacionada com o curso de formação e normalmente vincula-se à busca pelo conhecimento do mundo do trabalho ou à independência financeira dos pais. Os estágios tornam-se centrais quando o jovem procura experiência profissional relacionada à sua área de formação. Nesse momento, nota-se a influência das expectativas individuais, pois, numa forma institucionalizada de inserção e dentro de um mesmo grupo juvenil, devem ser consideradas as diversas trajetórias possíveis. Verifica-se que não há uma possibilidade única e generalista para compreensão desse processo, pois uma diversidade de caminhos se origina a partir da experiência de estágio, tornando ainda mais complexa a compreensão do conceito de inserção profissional.

\section{PALAVRAS-CHAVE}

Inserção profissional; Estágios; Administração; Mercado de trabalho; Jovens. 


\section{INTRODUÇÃO}

A passagem da universidade para o mercado de trabalho é parte integrante de um processo maior: a entrada na vida adulta. Segundo Galland (I990, 2000) e Dubar (200I), essa passagem é ao mesmo tempo profissional e sociocultural, devendo ser analisada numa perspectiva relacionada aos demais elementos da sociedade. Essa perspectiva congrega a ideia de que existem múltiplas juventudes vinculadas às dimensões temporais e culturais, e, consequentemente, diversos caminhos de inserção profissional.

No limite entre a universidade e o mundo produtivo, têm-se os estágios que, em décadas anteriores, foram criados pelas instituições de ensino como meio de complementação da formação e acesso ao mercado de trabalho. Atualmente, os estágios confirmam seu papel de "inserção profissional organizada", estruturada na convergência dos sistemas educativo e produtivo, em que a escola/universidade já incorpora aspectos de aprendizado prático à formação. Dessa forma, deixa de ser apenas um meio de formação das instituições de ensino e passa a ser reconhecido por organizações e estudantes como uma forma legítima (e às vezes necessária) para ingresso na esfera laboral.

No Brasil, a partir da década de I990, há um significativo aumento do número de jovens que chegam ao ensino superior, crescendo também a demanda por postos de trabalho qualificados. Enquanto a formação se amplia, notam-se uma redução da oferta de trabalho formal e a ampliação dos contratos flexíveis, evidenciando uma desconexão entre as estruturas educacional e ocupacional (HASENBALG, 2003).

As transformações em curso trazem uma nova complexidade para o tema: o número de estágios cresce, acompanhando o ritmo dos cursos de graduação (ASSOCIAÇÃO BRASILEIRA DE ESTÁGIOS, 2009). A lógica da formação perde espaço para o estágio como meio de flexibilização do trabalho e contratação de mão de obra de baixo custo, pois grande parte das atividades desempenhadas é de reduzido nível de exigência e desempenho (DOMINGO, 2002). Para alguns estudantes, o estágio torna-se fonte de renda, frequentemente tendo pouca relação com os conteúdos trabalhados no curso (TREVISAN; WITTMANN, 2002). Além disso, tem se tornado uma forma de intensa concorrência entre estudantes (LAURIS; SILVA, 2005). Tal concorrência faz com que algumas empresas elevem seus requisitos de recrutamento e estabeleçam processos de seleção com nível semelhante de exigência ao da contratação de profissionais para cargos efetivos (VILLELA ; NASCIMENTO, 2003).

Para compreender como essas transformações têm se refletido no processo de ingresso no mercado de trabalho, este estudo tem por objetivo analisar como 
ocorre a inserção profissional de estudantes de Administração de duas universidades do sul do país a partir da experiência de estágio. Para tanto, foram entrevistados 32 estudantes dos cursos de graduação em Administração de instituições públicas e privadas que relataram suas experiências de estágio, apontando suas implicações para a inserção profissional e suas expectativas de carreira futura.

Sabe-se que esse grupo não é representativo do total da população jovem, mas de um grupo profissional, delimitado pelo curso de formação, e, no caso do Brasil, um grupo que é visto como favorecido pelo tempo de estudo, quando comparado ao todo da população. Assim, essas trajetórias representam apenas algumas das formas pelas quais se dá a inserção profissional. Esse é um grupo profissional delimitado pelo curso de formação que, no Brasil, quando comparado ao todo da população, é visto como favorecido pelo tempo de estudo, além de não representar o total da população jovem do país. Dessa forma, essas trajetórias representam apenas algumas das formas pelas quais se dá a inserção profissional.

A seguir, apresenta-se a construção do conceito de inserção profissional, que dá base para a discussão do problema proposto.

\section{INSERÇÃO PROFISSIONAL}

A inserção profissional como tema de pesquisa é relativamente recente e surge com múltiplas interpretações para o momento da vida do indivíduo que busca representar: entrada na vida ativa, transição profissional, transição escola-trabalho, entre outros. Na França, a expressão "inserção profissional" começa a ser utilizada em meados dos anos I970 - para substituir a expressão "entrada na vida ativa" (entrée dans la vie active) utilizada na década anterior (NICOLE-DRANCOURT, I996) -, primeiramente em textos legislativos e depois em estudos sobre as dificuldades com que um número crescente de jovens se defronta quando termina a sua formação e pretende ingressar no sistema de emprego. Tais dificuldades contribuem para que a passagem do universo da educação/formação para o mundo do trabalho deixe de ser um acontecimento biográfico instantâneo e passe a ser um processo longo e complexo (NICOLE-DRANCOURT; ROULLEAU-BERGER, 2006). Para Charlot e Glasman (I998), a noção de inserção constitui, antes de tudo, uma noção de debate social e político, historicamente datado e semanticamente fluido, sendo de difícil separação da noção correlativa de exclusão que atribui uma visão de divisão particular do social: aqueles integrados ao emprego e à vida social e aqueles que são excluídos de ambos. Dessa forma, ressalta-se que a expressão "inserção profissional" é um conceito construído e adotado pelas comunidades 
política e científica francesas para explicar um fenômeno social que passa a ser de interesse das esferas política e científica.

Numa vertente econômica, Vérnières (I997, p. 3) define que a "inserção profissional é o processo pelo qual os indivíduos que jamais participaram da população ativa ingressam em uma posição estável no sistema de emprego".

O autor considera a inserção como um processo que tem como ponto final o encontro do posto formal no sistema de emprego. Essa noção de inserção profissional requer que sejam eliminados da análise os desempregados que, em um período anterior, já tenham passado pelo processo de inserção, bem como as mulheres que buscam ingresso no mercado mais tardiamente e jovens que realizam trabalhos sazonais durante os meses de férias, a fim de obter recursos para atividades de lazer no período de estudos do ano seguinte e que não estão ligados à sua formação profissional. O conceito de inserção profissional proposto está diretamente relacionado ao término dos estudos e à busca de um emprego com relação direta com o curso realizado (VÉRNIÈRES, I997).

Embora o autor proponha uma visão dinâmica da inserção, tratando-a como processo, e considere a interferência de diferentes atores e de normas institucionais características de cada sociedade, a visão predominante é econômica e centrada na maximização da capacidade produtiva do indivíduo. Como Vérnières (I997, p. II) salienta, "a inserção profissional é um processo que, além de sua eventual duração e da complexidade concreta, corresponde a uma finalidade econômica: aquisição de uma qualificação demandada pelo sistema produtivo". Nessa concepção, é apresentada apenas uma possibilidade de caminho pelo qual o indivíduo, economicamente interessado, deve prosseguir até que obtenha ou não o sucesso em sua empreitada rumo a um posto fixo.

Em outra perspectiva, Dubar (200I) trata o conceito de inserção profissional dentro de cada contexto histórico e cultural. Dessa forma, os percursos de inserção não podem mais ser compreendidos por meio de uma lógica única, baseada em uma racionalidade meramente econômica. No entanto, isso não significa que a inserção leve cada indivíduo a um percurso aleatório baseado em experiências individuais. É possível identificar lógicas socialmente construídas por meio da experiência familiar, escolar, relacional ou específica de alguns setores de formação. Essas lógicas típicas dependem dos contextos econômicos da inserção e das crenças compartilhadas por categorias de atores do sistema educacional e profissional (DUBAR, 200I).

Nessa perspectiva, a transição da escola/universidade ao trabalho/emprego não pode ser reduzida a mecanismos econômicos de compreensão de um mercado de concorrência perfeita, mas deve ser analisada como resultante de interações diversas e complexas que se situam geralmente em dois níveis: institucional e individual. A análise sociológica proposta pelo autor busca articular 
esses dois níveis de análise que correspondem ao sentido diferente da expressão "construção social".

A proposta de Dubar amplia a discussão sobre inserção profissional principalmente ao considerar que o conceito também está inserido em um contexto sócio-histórico, assumindo contornos diferenciados em cada país. Contribui também para a discussão metodológica do tema, a qual foca uma abordagem relacional com base tanto na história de vida dos atores quanto nos aspectos institucionais que influenciam e organizam o período de inserção de modo mais amplo.

Para compreender a inserção dos jovens, deve-se articular o ponto de vista estrutural - a sua vivência, delimitada por sua condição de origem - com a sua biografia - as peculiaridades de suas múltiplas experiências que decorrem da interação em seus contextos sociais (ambiente familiar, grupo de pares etc.) e do fato de eles viverem um momento do ciclo de vida dentro de uma geração sujeita às mesmas influências culturais de uma dada temporalidade histórica (DUBAR, 200I).

Neste estudo, entende-se a inserção profissional como um processo individual, coletivo, histórico e socialmente inscrito. Individual porque diz respeito à experiência vivenciada por cada sujeito na esfera do trabalho, suas escolhas profissionais e expectativas de carreira. É um processo coletivo por ser vivenciado de maneira semelhante por uma mesma geração, ou no interior de grupos profissionais. É histórico, pois se desenvolve ao longo de um período da vida do sujeito, sob a influência de elementos que marcam determinado momento no tempo e no espaço, como políticas públicas, mercado de trabalho, organização do sistema de ensino e políticas de recursos humanos e os pontos de vista "empresariais" sobre as relações entre educação e trabalho. Está inscrito em um dado contexto socioeconômico e cultural, em que, além dos elementos institucionais, há influência das construções e das representações sociais que os indivíduos desenvolvem em relação a esta inserção profissional.

Assim, a compreensão deste processo requer que se leve em conta aspectos individuais e institucionais, bem como o contexto em que estes se inscrevem. Quanto ao contexto, como propõe Dubar (200I), a inserção profissional é uma construção histórica, inscrita em um contexto sociocultural. Logo, aspectos da conjuntura econômica, da estrutura demográfica e ocupacional de cada região ou país, dos níveis de formação e de desenvolvimento tecnológico e industrial são a moldura do ingresso do jovem no mercado de trabalho.

Entre os elementos individuais, consideram-se a origem familiar do jovem, as experiências de trabalho, as expectativas profissionais e as estratégias de inserção empreendidas. Como origem familiar, entendem-se a etnia, a escolaridade, a profissão dos pais e os valores sobre o trabalho considerados pela família. $\mathrm{Na}$ experiência profissional, tem-se a biografia da relação do sujeito com o mundo do 
trabalho, considerando-se, além dos conhecimentos práticos e da formação de redes de relacionamento, seus encantamentos e suas desilusões vivenciados na esfera laboral ao longo de sua trajetória. As expectativas profissionais permitem analisar, com base nas experiências vividas, como o sujeito está se preparando para a continuidade de sua profissão e como ocorre a inserção profissional nesse processo.

Quanto aos aspetos institucionais, as regulamentações estatais dizem respeito às leis que pautam como deve ocorrer a entrada no mercado de trabalho (idade mínima, formação para cargos específicos, leis que orientam as relações de trabalho) e às políticas governamentais para a sua inserção em dado momento. Embora essas duas estejam ligadas à esfera governamental, elas representam aspectos distintos: enquanto as primeiras apresentam um caráter mais amplo e duradouro, sugerindo normas de regulação do mercado, as políticas têm duração determinada e são voltadas para segmentos ou setores específicos da população.

Ainda no quadro institucional, merecem destaque as políticas de gestão de recursos humanos das empresas, que podem assumir formas distintas, o que dependerá do tamanho da organização, do setor de atuação ou dos grupos profissionais considerados diferenciais para o negócio ou em que há carência. As organizações profissionais podem ter maior ou menor influência, dependendo da antiguidade e integração de cada grupo profissional. No caso de médicos e advogados brasileiros, essas instituições têm papel central na regulamentação da profissão e, consequentemente, na inserção profissional, enquanto, para profissões mais recentes, ainda não há tal nível de organização.

As organizações de mediação também estão assumindo papel importante desde a década de I990. Assim, o meio pelo qual é feito o recrutamento - mídia ou empresas especializadas - também assume papel importante para compreensão da inserção profissional (GUIMARAES, 2008). No caso dos estágios no Brasil, os agentes de integração atuam no agenciamento de vagas, tornando-se atores centrais no seu processo de organização. Também se destaca o papel das instituições de ensino como atores que atuam direta ou indiretamente sobre o mercado de trabalho, contribuindo para estabelecer normas que podem ser originadas fora da estrutura daquele mercado. Os estágios, foco deste trabalho, constituem um meio de formação que se desenvolve em relação com o mercado, servindo como um momento de socialização dentro das regras de uma profissão, mas sendo desenvolvidos sob a tutela das instituições de ensino.

Entretanto, apesar dessa relação com o mercado de trabalho, o estágio não constitui uma relação de trabalho propriamente dita, uma vez que não tem por fim um resultado produtivo para as atividades desempenhadas pelo estudante. A relação predominante é a de ensino, atividade que não tem fins produtivos para a empresa e que atende à finalidade pedagógica das instituições de ensino. 
Sob esse aspecto, destaca-se a atuação do Estado que legisla sobre a prática do estágio, determinando como este deve ser desenvolvido para que prevaleçam os aspectos pedagógicos.

\section{OS ESTÁGIOS: ASPECTOS GERAIS}

Os estágios (obrigatórios ou não) ${ }^{2}$ objetivam atender às demandas de formação prática requeridas pelas organizações. Além disso, ao longo dos anos, tornaram-se importantes meios de inserção profissional progressiva, estimulando escolas e universidades a ampliar sua prática. O principal objetivo de alguns estágios em semestres ou anos iniciais é a familiarização - ou iniciação - às atividades do curso no qual o estudante está inscrito, enquanto os realizados mais ao final da formação exercem função importante como meio de inserção profissional (RITNNER, I999).

Essa definição predominante nos livros que abordam o tema e que valoriza o aspecto formativo dos estágios é referendada pela Lei $\mathrm{n}^{\circ}$ II.788 que, em seu artigo $I^{\circ}$, destaca:

Estágio é ato educativo escolar supervisionado, desenvolvido no ambiente de trabalho, que visa à preparação para o trabalho produtivo de educandos que estejam freqüentando o ensino regular em instituições de educação superior, de educação profissional, de ensino médio, da educação especial e dos anos finais do ensino fundamental, na modalidade profissional da educação de jovens e adultos.

No texto da nova lei, também é enfatizado que o estágio é uma via de preparação para o mercado de trabalho, ou seja, incorpora a função de responsável pela inserção profissional que era ausente na lei anterior (de I977). Tal aspecto reforça o reconhecimento do estágio como um meio institucionalizado de acesso ao emprego no campo de formação, algo que decorre do crescimento das matrículas no ensino superior, que deixa de ser um critério diferencial para ingresso e passa a contar com intensa concorrência, tornando ainda mais importante a experiência de estágio para aquisição de experiência prévia e conhecimento prático.

2 Os estágios obrigatórios ou curriculares supervisionados são vinculados à(s) disciplina(s) do currículo pleno e estão previstos como atividade integrante do curso, permitindo aos estudantes dos cursos de graduação seu primeiro contato com o ambiente de trabalho. Os não obrigatórios são procurados voluntariamente pelo estudante, não representando créditos a serem integralizados para conclusão do curso, mas agregando aprendizado e experiência. 
No entanto, por se localizar na fronteira entre a formação e a atividade produtiva, o desconhecimento ou o mau entendimento sobre o estágio leva a uma multiplicidade de práticas que nem sempre priorizam a formação profissional do estudante.

Domingo (2002), ao analisar empresas francesas, destaca que atualmente os estágios ganham quatro lógicas de compreensão: inserção profissionalizante, período de teste, ajustamento quantitativo da mão de obra e ajustamento qualitativo. No primeiro caso, permanece a lógica original pela qual os estágios foram criados: a inserção profissional e qualificação prática de jovens estudantes. No segundo caso, as empresas utilizam o estágio como período de avaliação de possíveis futuros empregados; a intenção nesse caso é refinar a seleção por meio de um conhecimento mais profundo do pretendente à vaga. $\mathrm{Na}$ terceira e quarta lógicas, não há intenção de formalizar contrato e integração do estudante ao seu quadro de trabalhadores. No caso do ajustamento quantitativo, a empresa busca atender à demanda numérica de trabalhadores por um determinado período; nesse caso, o estágio se aproxima de um contrato temporário. Qualitativamente, o objetivo principal por parte da empresa é a busca de pessoal qualificado por um custo inferior ao encontrado no mercado, constituído por profissionais já formados.

Essa variedade de compreensões do estágio é fundamental para as peculiaridades de cada caso. No Brasil, os estágios que mais crescem são os não obrigatórios (ASSOCIAÇÃO BRASILEIRA DE ESTÁGIOS, 2009), que não são requisitos para conclusão do curso. A maior parte dos estudantes encontra as oportunidades via agentes de integração, que assumem a responsabilidade de intermediadores das vagas. O estágio é realizado paralelamente ao curso com contrato de duração de seis meses, podendo ser renovado até o limite de dois anos. Para alguns estudantes, sobretudo de instituições particulares, os estágios não são apenas uma forma de aprendizado, mas também meio de custear suas despesas (alimentação, transporte) e, em alguns casos, pagar o próprio curso.

O aumento das demandas por qualificação e experiência no mundo do trabalho amplia a abrangência de tempo e conteúdo dos estágios (TREVISAN; WITTMANN, 2002). Estes passam a ser ofertados diretamente pelas empresas aos estudantes, seja via canais de recrutamento tradicionais (anúncios em jornais, sites, murais das instituições de ensino), seja por meio de agências especializadas no recrutamento de estagiários, os agentes de integração.

Alguns estudos apontam que os estágios estão muito distantes de seu objetivo pedagógico original, constituindo principalmente uma fonte de renda para os estudantes e obtenção de mão de obra de baixo custo para empresas (públicas e privadas), uma vez que grande parte das atividades desempenhadas é de baixo nível de exigência e desempenho (AMORIM, I995), muitas vezes tendo 
pouca relação com os conteúdos trabalhados no curso (TREVISAN; WITTMANN, 2002), além de constituírem uma forma de intensa concorrência entre estudantes (LAURIS; SILVA, 2005). Há, ainda, empresas com programas de estágio mais estruturados que selecionam estagiários com o mesmo nível de exigência da contratação de profissionais para cargos efetivos (VILLELA ; NASCIMENTO, 2003).

De maneira geral, esses estudos apontam que as múltiplas lógicas de compreensão do estágio apresentadas por Domingo (2002) também estão presentes no Brasil e podem ser uma complementação da formação, um meio de inserção profissional, mão de obra precária ou uma fonte de renda para custeio dos estudos, como foi levantado nos estudos citados. Além disso, no caso brasileiro, o crescimento do número de vagas do ensino superior, sobretudo nos cursos de Administração, contribui para a formação de diferentes práticas de estágio. Na próxima seção, apresenta-se o método utilizado para alcançar os resultados do estudo.

\section{PROCEDIMENTOS METODOLÓGICOS}

Este estudo segue uma postura construtivista, assumindo que existem mais fronteiras entre o sujeito e o objeto, aceita-se e considera-se fundamental a intervenção do pesquisador no fenômeno analisado (LE MOIGNE, 2007). O conhecimento não é visto como algo pronto para ser descoberto na realidade, mas algo construído pelo pesquisador na medida em que seu caminho é trilhado (PATTON, 2002). Contudo, essa forma de pensamento não consiste em simples relativismo de ideias, mas no reconhecimento do potencial de geração de conhecimento sob um enfoque construtivista.

Ao seguir essa orientação para a compreensão do processo de inserção profissional, buscou-se ouvir cuidadosamente os estudantes acerca das diferentes experiências laborais, com destaque para os estágios, com a finalidade de interpretar os significados que estes atribuem a este mundo. Os pesquisadores tinham contato direto e/ou indireto com os estágios por meio de conversas com alunos e amigos, além de sua própria experiência, evidenciando uma vinculação com o tema.

Na seleção dos entrevistados, levou-se em conta que o tema em questão se situa na transição entre universidade e mercado de trabalho. Assim, buscou-se entrevistar jovens que haviam tido pelo menos uma experiência de estágio, sem focar um momento particular do curso. Alguns entrevistados estavam entre o sexto e o décimo semestres, outros eram recém-formados.

O ponto de partida para encontrar os jovens para entrevistar foi nas instituições de ensino. Apesar da crítica ao efeito institucional que tal abordagem 
possa causar sobre os resultados, é importante considerar que o modo como cada universidade trata o estágio também pode interferir na sua forma de vivência. A separação entre o público e o privado surgiu como uma preocupação de contemplar critérios de diferenciação no ensino superior presentes no Brasil. A escolha de instituições de Porto Alegre levou em conta que aspectos regionais também contribuem para a formação dos mercados de trabalho.

Apesar de as instituições de ensino superior situarem-se em Porto Alegre, se forem consideradas as cidades de residência de alguns entrevistados, bem como a localização das empresas em que estagiaram, o contexto da pesquisa é a região metropolitana da cidade. Segundo dados do Instituto Brasileiro de Geografia e Estatística (IBGE, 20Io), a região metropolitana de Porto Alegre tem a quarta maior população do país (atrás de São Paulo, Rio de Janeiro e Belo Horizonte) e está entre as cinco regiões utilizadas pelos órgãos nacionais de pesquisa de emprego e desemprego, tais como Instituto de Pesquisas Econômicas Aplicadas (Ipea) e Departamento Intersindical de Estatística e Estudos Socioeconômicos (Dieese). Dessa forma, reúne características relevantes que comprovam a pertinência da análise dessa região para compreender o mercado de trabalho no Brasil.

Chegou-se ao número de 32 sujeitos, pois a pesquisa se desenvolveu baseada na ideia de singularidade e coletividade, uma vez que os atores são ao mesmo tempo relativamente singulares e análogos (LAHIRE, 2002), permitindo o alcance do chamado "ponto de saturação". Isso significa que, após certo número de entrevistas, o pesquisador percebe que se encerra a apreensão de novos elementos sobre o tema pesquisado. O pesquisador não pode estar seguro de ter atingido a saturação senão na medida em que, conscientemente, tenha procurado diversificar seus informantes, dentro do contexto em que situa sua pesquisa.

Durante as entrevistas, verificou-se que parte dos estudantes da universidade pública havia iniciado sua formação numa instituição particular, levando à redução dos entrevistados da instituição privada devido à repetição das informações. Os estudantes tinham entre 2I e 28 anos. A Tabela I apresenta a divisão por gênero.

\section{TABELA I}

DISTRIBUIÇÃO DOS ENTREVISTADOS POR GENERO

\begin{tabular}{lccc} 
& HOMENS & MULHERES & TOTAL \\
\hline Universidade pública & 15 & 7 & 22 \\
Universidade privada & 6 & 4 & 10 \\
\hline
\end{tabular}

Fonte: Elaborada pelos autores. 
As entrevistas seguiram um roteiro, mas não de forma rígida e estruturada, a fim de ressaltar a história profissional do estudante; o desenrolar das questões dependia da interação com cada jovem, de sua disposição de falar e de como os temas abordados surgiam na conversa. Foram adotadas atitudes diretivas e não diretivas, de questionamentos e escuta ativa e sistemática, buscando o afastamento da simples não intervenção da entrevista e do caráter estrito e direto do questionário (BOURDIEU, I983).

A escolha dos depoimentos pessoais como técnica de coleta de dados significa que o material para análise foi construído por meio de uma narração na qual o entrevistado fala sobre sua vida (suas práticas, sua opinião, seus gostos e suas emoções) por meio da estrutura de uma interação pesquisador/pesquisado. A aceitação mútua e a interação não permitem pensar que pesquisador e pesquisado sejam iguais, mas sim que a diferença gerada pela relação é importante para a formação do diálogo. Apesar de seu comprometimento ético e político, é ele que conduz e direciona a entrevista; caso contrário, permaneceria preso no discurso do entrevistado (QUEIROZ, I988).

A maior parte dos jovens entrevistados morava com os pais ou recebiam ajuda para se manter, embora relatasse a urgência em conseguir uma atividade remunerada para alcançar a independência financeira. Desses jovens, I9 estudaram em escola particular durante o ensino médio e cinco cursaram parte em escola pública e parte em particulares. Corrobora-se a tendência à inversão salientada por Hasenbalg (2003), ou seja, o estudante que cursa ensino médio em instituição particular migra para a pública no superior e vice-versa. Salienta-se que não se pode generalizar, visto que foram encontrados casos em que não se verifica essa relação.

Um aspecto importante sobre o grupo de entrevistado foi a pouca representatividade de estudantes não brancos, pois foi possível entrevistar apenas uma estudante negra. Considerando a formação da população do país, onde se verifica que uma parcela importante da população é não branca, a falta de representantes desse grupo evidencia a dificuldade que estes encontram para ingressar no ensino superior e o caráter elitista do curso, aspecto destacado nos estudos de Hasenbalg (2003).

$\mathrm{Na}$ análise de entrevistas, buscou-se compreendê-las como a materialização do social em palavras. Os depoimentos contêm informações, evocações e reflexões que precisam ser articuladas, e como as transcrições não são autoevidentes, cabe ao pesquisador este papel central. As operações de classificação e de comparação e a atribuição de significados às falas dos entrevistados foram realizadas por meio da análise de práticas discursivas, que é a busca descritiva, analítica e interpretativa do sentido que o indivíduo atribui às suas mensagens (SPINK, 2004). 
Assim, a partir da leitura das entrevistas, buscou-se traduzir as narrativas individuais em categorias de análise que demonstrassem configurações discursivas por meio da confrontação com a experiência dos entrevistados e com o contexto local mais amplo. A análise é o recorte de uma totalidade nas partes que a formam, que são então apreendidas na sequência que apresenta em sua naturalidade para num segundo momento serem restabelecidas em uma nova coordenação; forma esta que foi validada pelos participantes.

Optou-se por abordar a história da inserção profissional dos entrevistados como alternativa para articular a dimensão individual e de vida vivenciada por uma pessoa em relação ao contexto social mais abrangente. Na aplicação desse método, a apreensão da experiência de estágio não é vista apenas como um repertório de acontecimentos sucessivos, mas também como um acontecimento vivido em determinado tempo e lugar e sob múltiplas circunstâncias. Após a análise de cada entrevista, buscou-se analisar o conjunto das entrevistas, de modo que se destaque a similaridade no processo de inserção por meio do estágio vivenciado pelos estudantes.

A seguir, são apresentadas as interpretações do processo de inserção profissional, na transição da universidade ao trabalho. Contemplam-se três momentos: o primeiro contato com o mundo do trabalho, o estágio e o foco na profissionalização, e os planos para o futuro.

\section{EXPERIÊNCIA DE ESTÁGIO E A INSERÇÃO PROFISSIONAL DOS ESTUDANTES DE ADMINISTRAÇÃO}

Deve-se destacar que, no caso estudado, tem-se a juventude universitária dos cursos de Administração. Esse grupo já foi representado exclusivamente pelas classes mais favorecidas. No entanto, com o grande aumento dos cursos de Administração nas últimas décadas, o perfil socioeconômico dos estudantes tem se diversificado. Sabe-se que os estágios não são a única forma de inserção profissional para esses estudantes, mas trata-se de uma forma reconhecida para o ingresso na sua área de atuação para os mais jovens.

Para compreender a situação, destacam-se alguns elementos do contexto social mais amplo que marcaram o Brasil nos últimos anos. As mudanças econômicas e sociais ocorridas em meados do século XX caracterizam a passagem de um país agrário a uma nação predominantemente urbana, como a ampliação da industrialização, escolarização e urbanização. Entre os aspectos importantes para o desenvolvimento do país, está o crescimento do ensino superior que 
ocorre principalmente a partir da década de I990. No entanto, esse crescimento deu-se principalmente pela expansão do setor privado de ensino, que assume características mercantis e aumenta rapidamente, invertendo a relação de carência que havia de profissionais formados para um quase excesso de graduados.

Embora os níveis de escolarização tenham crescido no país, esse incremento da escolaridade não produz uma alteração do padrão de articulação entre estudo e trabalho, poucos se beneficiam de uma permanência prolongada na escola e de um ingresso tardio no mercado de trabalho. Além disso, a estrutura de emprego não tem o mesmo crescimento na qualidade nem na quantidade dos postos de trabalho. Nota-se uma possível desvinculação entre estrutura ocupacional e educacional com a população mais bem formada, principalmente os jovens que precisam enfrentar oportunidades de emprego inferiores no mercado de trabalho (HASENBALG, 2003).

Quando se analisam os cursos de Administração, observa-se a tendência de crescimento desordenado, sendo um ensino em que nem sempre predomina a qualidade. Essa massificação dos cursos de Administração não acontece nos países desenvolvidos, e acredita-se que isso tenha ocorrido no Brasil devido à facilidade para abrir um curso, visto que são necessários poucos investimentos em ativos fixos. Além disso, há instituições em que os alunos podem estudar em meio período, o que favorece o crescimento dos cursos noturnos (BERTERO, 2007).

O crescimento das matrículas aumenta o número de alunos que buscam entrar no mercado de trabalho durante o curso superior. Entre as principais formas de ingresso, estão os estágios que no Brasil têm algumas particularidades, tais como a possibilidade de longa duração (até dois anos), a falta de acompanhamento das instituições de ensino e a presença dos agentes de integração, que muitas vezes tratam a alocação de vagas como negócio. Essas características contribuem para um modelo de estágio em que a base principal está na relação entre estudante e empresa.

Com base nas entrevistas, pôde-se observar que os estágios apresentam uma estreita relação com o processo de inserção profissional dos estudantes de graduação em Administração, embora nem sempre estejam vinculados à sua primeira atividade na esfera do trabalho. Os desdobramentos dessa experiência se dão de maneira contínua, iniciando com atividades simples, voltadas à primeira socialização na empresa até alcançarem uma dimensão em que os critérios de seleção do estágio são mais elevados.

A seguir, são apresentadas três seções que caracterizam os principais achados da pesquisa, apontando o processo de inserção dos estudantes a partir da experiência de estágio. Esta ocorre em três momentos: a primeira entrada, na qual o jovem aprende as regras gerais do funcionamento do mercado de trabalho e do 
meio organizacional; a segunda, que tem por objetivo desenvolver as atividades ligadas ao curso; e o terceiro momento, de definição dos diferentes caminhos que se estabelecem a partir dessas experiências.

\subsection{A "PRIMEIRA" ENTRADA NO MERCADO DE TRABALHO}

O ingresso no ensino superior, ou até mesmo antes, a conclusão do ensino médio e a aprovação no concurso vestibular são considerados marcos que indicam o momento de buscar uma oportunidade no mercado de trabalho. A principal razão apontada pelos entrevistados foi a necessidade e/ou independência financeira, mas também um dever social de ingressar na esfera produtiva. $\mathrm{O}$ início de uma atividade profissional nesse momento da vida do estudante surge como um imperativo, sendo representado por expressões como "necessidade", "já estava na hora", "estava ficando velha”, indicando que se deve entrar no mercado cedo, como é sintetizado a seguir:

Acho que tem uma cultura geral. No primeiro semestre, todo mundo que entra ainda está conhecendo, é um "ambiente de festa", tudo é mais descontraído, e a partir do segundo, agora é hora de pensar um pouco mais sério, de crescer. Daí mais forte do que no ensino médio a pressão familiar também, buscando experiência, está na hora de começar (Wilson, 22 anos).

O curso universitário normalmente ocorre em paralelo com alguma atividade profissional. Essa necessidade de inserção é vista tanto como um meio de garantir maior liberdade e independência financeira quanto o momento de iniciar a construção de uma carreira por uma socialização inicial no ambiente de trabalho.

Nesse momento, o papel da família é expressivo. Para alguns estudantes, os familiares são fortes incentivadores por cobrar, às vezes, a entrada no mercado de trabalho. Para outros, embora não haja pressão, quando o estudante se dispõe a procurar um trabalho, a família oferece oportunidades nas suas organizações ou recorre às suas redes pessoais: "Meus pais me deram muito apoio, porque viram a importância de eu começar a entender o valor do dinheiro, o valor do trabalho em si" (Janaína, 24 anos).

Essa pressão, ou estímulo familiar, evidencia que o término do ensino médio como marco de ingresso no mercado de trabalho é uma construção social não apenas da geração entrevistada, mas algo que vem da geração anterior e está presente em diferentes classes sociais. Galland (I990), ao analisar os jovens franceses, destaca como marcos formadores da vida adulta a saída da casa dos pais, 
o ingresso no mundo do trabalho e o casamento. Posteriormente, em função da ampliação do tempo de estudos, a entrada mais tardia das novas gerações na esfera do trabalho e o crescimento dos contratos atípicos, o autor relata que essa passagem estava sendo fluida e organizada. Os jovens ingressam mais de uma vez no mercado e quando não encontram um contrato por tempo indeterminado retornam à casa dos pais até encontrarem uma nova oportunidade.

No caso dos estudantes entrevistados, a saída da casa dos pais está relacionada com a necessidade de estudar e as aspirações profissionais futuras, já que Porto Alegre se destaca no Rio Grande do Sul por apresentar universidades reconhecidas pela qualidade, além de amplas possibilidades de trabalho na cidade e em sua região metropolitana. O ingresso na esfera laboral se destaca, entre outros marcos, como o principal elemento de início da vida adulta, esfera na qual os estudantes vão assumir responsabilidades e construir uma carreira. Para outros estudantes, o ingresso na faculdade é o momento de entrar na vida ativa, e, nesse caso, eles frequentemente procuram estágios. Outros, no entanto, consideram que, para se candidatarem a estágios, é necessária uma experiência prévia e, por isso, recorrem a atividades voluntárias, como monitorias ou empresas juniores.

Nessa primeira etapa da inserção, tanto as principais contribuições quanto os desafios encontrados estão relacionados com o conhecimento das "regras" que dirigem o ambiente interno da organização: hierarquia, responsabilidade com horários e compromissos, adaptação da linguagem e trabalho com pessoas fora do ambiente familiar e escolar. Há pouca preocupação com o desenvolvimento de atividades ligadas ao curso e com sua futura carreira profissional. O aprendizado está mais voltado para aspectos gerais da vida organizacional e não para uma estratégia estruturada de ingresso em que as experiências contribuirão para o enriquecimento do currículo e acesso a melhores oportunidades. O jovem busca ser reconhecido e aceito nesse novo universo; logo, o simples fato de conseguir uma atividade já representa uma conquista.

As principais contribuições, por sua vez, estão relacionadas à construção do conhecimento sobre o funcionamento do mundo do trabalho, saber como pensar e agir de acordo com o mundo organizacional e o aprendizado de um novo mundo que se organiza de modo diferente ao da escola e da família. Essa etapa é vista como transitória, mesmo para os estudantes que encontram na primeira experiência uma oportunidade de emprego formal, isso porque não consideram como inserção profissional efetiva, pois trata-se de um momento de aprendizado, normalmente em atividades não vinculadas com seus objetivos profissionais. 


\subsection{A "SEGUNDA" ENTRADA: EM BUSCA DE UMA CARREIRA}

Depois de os estudantes conhecerem o ambiente de trabalho, os critérios para a seleção da próxima experiência se tornam mais elevados em termos de expectativas financeiras e profissionais. O estágio é reconhecido como o meio mais propício para encontrar uma atividade relacionada com o curso de formação e de ingressar em uma grande empresa.

Bolsa auxílio, nome da empresa, atividades relacionadas à formação. Porque via nos estágios a forma de aprender (Carlos, 25 anos).

Procurei um estágio na área em que eu tinha um maior interesse, no caso finanças. Usei como critério, principalmente, se eu iria aprender naquele estágio e se eu tinha possibilidade de crescer e ter algum desenvolvimento lá. Por último pensava em remuneração (Mathias, 23 anos).

A partir da segunda oportunidade, os critérios de escolha de estágio vão se ampliando. Após terem o esboço das principais características do mercado de trabalho e das expectativas organizacionais e ao começarem a elaborar a ideia da carreira, os estudantes voltam-se para áreas específicas, procuram bolsas de maior valor e, em grande parte dos casos, pleiteiam uma vaga numa grande empresa. Além disso, já dispõem de uma credencial de diferenciação nesse mercado - a experiência - que lhes permite postular vagas de estágio consideradas mais seletivas e de difícil ingresso.

Embora nem todos se orientem para o ingresso em grandes empresas, compartilha-se a ideia de que os estágios que possibilitam maior aprendizado e melhores possibilidades de carreira são oferecidos por elas. Essa imagem construída durante as aulas e na leitura das revistas da área, que valoriza as multinacionais de marcas conhecidas, cria um modelo de inserção para o estudante de Administração que passa pela grande corporação. Alguns jovens apontaram que, mesmo ao término do curso, não se sentiam preparados para postular vagas em grandes empresas, pois consideravam muito elevados os requisitos indicados nos anúncios de estágio.

A segunda experiência de trabalho, diferentemente da primeira, contribui para o início da formação da carreira do estudante. É o momento em que busca atividades que estejam de acordo com suas expectativas e de assumir maiores responsabilidades com resultados. 
Conheci mais do dia a dia, entrei em contato com mais pessoas [...] falei com fornecedores [...] precisei defender ideias [...] o ambiente exigia uma postura mais profissional [...] o trabalho tinha regras e etapas bastante organizadas na qual era preciso seguir [...] (Marcelo, 22 anos).

De acordo com os entrevistados, os principais desafios são a complexidade dos processos, a exigência de metas e as responsabilidades assumidas. A relação com o curso, na maioria das vezes, permite um aprendizado mais profundo dos conteúdos tratados em sala de aula, além de solidificar as competências tácitas da área de atividade. Também é o momento de testar ramos específicos da profissão que são de maior interesse, mas que ainda geram dúvidas. A partir do primeiro estágio na área, os estudantes podem diversificar experiências, sendo o estágio um período de teste e confirmação de suas expectativas profissionais.

O contato com pessoas (colegas da organização, fornecedores ou clientes) contribui para a formação de redes de relacionamento que permitem um conhecimento mais amplo do mercado e favorecem o ingresso em futuras oportunidades como efetivos. É a partir da segunda experiência de estágio que o estudante vai definindo o caminho para sua futura carreira profissional.

Nesse período, buscam diversificar atividades e conhecer diferentes empresas, setores e áreas de atuação, de modo que possam formar uma carreira prévia que, registrada no currículo, contribuirá para um emprego efetivo no futuro. As experiências positivas reforçam sua convicção acerca do caminho a ser seguido. As negativas fazem com que esses estudantes reavaliem as possibilidades disponíveis. $\mathrm{O}$ estágio na grande empresa nem sempre corresponde às expectativas desses jovens, seja pelas tarefas que desenvolvem, seja pelo ambiente que encontram. Mesmo nas multinacionais nem sempre encontram as esperadas atividades de alto valor agregado e ligadas ao aprendizado gerencial, pois o estágio, muitas vezes, é constituído de tarefas operacionais ou burocráticas. Tais atividades são percebidas como de pouco valor pelo estudante e, quando isso ocorre numa grande empresa, podem contar negativamente, pois frustram as expectativas de carreira naquele tipo de organização.

Sim, saí e fui buscar. Eu gostei de trabalhar no Integrar, tinha oportunidade ali dentro, mas eu vi que era muito instável. Porque em seis meses que eu fiquei lá, muita gente que era funcionário foi mandado embora sem motivo aparente, aí eu vi que não era aquilo que eu queria para mim. A empresa era boa, mas tinha esse porém, não tinha estabilidade, não tinha uma garantia. Era mandado embora de forma arbitrária. Estavam cortando despesas. Podendo substituir, estão te substituindo (Celina, 22 anos). 
Outros estudantes, apesar de experiências pouco proveitosas e de baixo aprendizado, consideram que a passagem por uma grande empresa ajuda a valorizar o seu currículo, pois o nome da organização serve como uma forma de certificação de competência. Dessa forma, aceitam mesmo atividades não relacionadas com o curso e o clima de trabalho tenso, a cobrança por metas e uma vivência profissional que interfere na vida pessoal e nos estudos.

Nesse momento, a expectativa do estudante para a formação da carreira é encontrar estágio que valorize o aprendizado e contribua para sua inserção profissional. No entanto, alguns deparam com estágios que têm por objetivo a ocupação temporária de um posto de trabalho para realização de atividades rotineiras e, muitas vezes, sem relação com o curso. Alguns jovens aceitam esses estágios por necessidade financeira ou para adicionar o nome da empresa aos seus currículos; para outros, é um choque que os leva a mudar radicalmente suas expectativas de futuro profissional, redirecionando seus interesses para concursos públicos, para o empreendedorismo ou para o ensino e a pesquisa.

Esses diferentes caminhos serão aprofundados posteriormente, pois acredita-se que sejam formas de inserção diferentes daquelas que estão sendo descritas aqui.

\subsection{PERSPECTIVAS DE CARREIRA A PARTIR DA VIVÊNCIA DOS ESTÁGIOS}

A partir da experiência de estágio, os estudantes constroem sua base de carreira e já direcionam os caminhos que pretendem seguir. Com base na análise das entrevistas, foram encontrados cinco caminhos de inserção profissional e formação de carreira decorrentes da experiência de estágio.

\subsubsection{Carreira acelerada na grande empresa}

Para a maior parte dos entrevistados, a primeira experiência profissional é semelhante, permitindo uma socialização inicial no mundo do trabalho que pode ser via estágio ou outra função em que se encontram como aprendizes. A segunda experiência já é voltada para a grande empresa e os grandes processos seletivos, buscando ampliar e/ou testar seus conhecimentos. Se a vaga está de acordo com suas expectativas, procuram ser efetivados, assumindo maiores responsabilidades que lhes permitam continuar com o desenvolvimento acelerado que almejam. Se não estiver, logo que chegam ao "máximo aprendizado" que essa organização pode proporcionar, buscam outro estágio que possibilite maior crescimento. 
Segundo a proposta de Dubar (200I), que valoriza elementos socioculturais da formação para compreensão, esse grupo é formado principalmente por homens, cujos pais têm curso superior completo e que cursaram ensino médio em escolas particulares, notadamente os tradicionais colégios de Porto Alegre. Para esses jovens, o processo de inserção não se encerra com a efetivação na grande empresa; ele continua, muitas vezes, com o ingresso em programas de trainee até que alcancem algum posto na alta gerência.

Agora eu estou com um cargo legal, estou fazendo uma experiência bacana, mas eu quero um cargo de gestão. A faculdade me deu esta formação para isto. Não vou parar minha educação, o próximo passo é um pós. Para o futuro quando eu acabar me formando quero tentar um programa de trainee, que eu acho que é muito válido, tanto para valores financeiros, os caras estão reconhecendo bem e também eles estão te preparando para assumir uma gestão. Então tu não precisa ficar ali batalhando como um analista acho que eles dão esta brecha. Então para mim a curto prazo é um processo de trainee numa empresa multinacional (Danilo, 22 anos).

Para esses jovens, a efetivação é apenas mais uma etapa do processo de inserção profissional. Os programas de trainee surgem na sequência do processo e, como os estágios, acabam por institucionalizar um processo de inserção cada vez mais rigoroso e seletivo. Esses estudantes focam desde cedo o desenvolvimento profissional e se incomodam quando o crescimento na empresa não ocorre no curto prazo. É interessante marcar que esse discurso, embora permeie a fala de vários entrevistados, aparece de maneira mais evidente entre os estudantes homens, brancos e da universidade pública, que é uma das referências nacionais na área de Administração. As mulheres da escola pública, bem como os estudantes da faculdade privada, quando se manifestam sobre esse caminho, têm uma postura mais moderada, considerando outras oportunidades.

Não foi planejada, passou a ser quando saí do órgão público. Hoje tenho me organizado melhor. [...] Tenho dois caminhos: iniciativa privada e "o sangue pela empresa" ou iniciativa pública: adequação ao sistema e possibilidade de continuar me graduando após o curso. Sinceramente tenho dúvidas a respeito desses caminhos, tenho medo de "emburrecer" num carguinho público que não me proporcionará crescimento (Janaina, 24 anos).

Alcançar um posto gerencial em uma grande empresa faz parte do discurso da inserção que está sendo construído na maior parte das grandes universidades, reforçando a competição entre os estudantes e aumentando as diferenças 
que existem entre eles. As seleções de trainee a que os estudantes se referem são processos em que milhares de estudantes competem por uma vintena de vagas. Aqueles que são aprovados são tratados como vitoriosos, merecedores de destaque e reconhecimento. Quando se observa a conversa entre alguns estudantes em final de curso, nota-se que a aprovação em um programa de trainee é tratada como uma credencial a mais, um diferencial no mercado competitivo do qual participam e no qual querem se destacar.

Entre os elementos sociais que caracterizam esse grupo, identifica-se a predominância de valores associados ao trabalho, à carreira e ao rápido crescimento profissional. Tais valores são reforçados dentro das instituições de ensino nos cursos de Administração, onde alguns professores incitam a concorrência e a importância daqueles que são reconhecidos como vencedores. Também as revistas da área enfatizam a necessidade de vencer e a importância de atuar em grandes empresas.

Para os estudantes desse grupo, o estágio representa uma etapa a ser cumprida e deve ser trabalhado como credencial capaz de gerar diferenças no currículo. A experiência deve ser proveitosa para a carreira futura, pouco importando o respeito à legislação do estágio e as regras da universidade, que muitas vezes é considerada como um empecilho para seu desenvolvimento profissional. O estágio considerado bom tem processo seletivo com requisitos elevados (que os diferenciam da maioria dos estudantes), com tarefas complexas, grandes responsabilidades e cobrança por resultados. No entanto, a efetivação não é o principal objetivo, visto que a consideram apenas mais uma etapa de sua carreira.

Com base na proposta de inserção apresentada por Vérnières (I997), podese considerar que o processo para esses jovens se conclui antes mesmo do término do curso de graduação. No entanto, para esses estudantes, a inserção profissional não se encerra com o emprego de carteira assinada, mas com a conquista de um posto de destaque na carreira que estão construindo. Assim, evidencia-se a necessidade de buscar o conceito de inserção profissional mais amplo e analisar como ocorre esse processo para o indivíduo e na sociedade da qual participa.

Todos os demais estudantes reconheceram que esse seria o "modelo de inserção esperado" para o curso de Administração. No entanto, alguns deles não se reconhecem preparados ou não querem enfrentar a competição e o desenvolvimento acelerado, baseando seu processo de inserção em caminhos diferentes.

\subsubsection{A efetivação e o desenvolvimento dentro na empresa}

As grandes empresas também aparecem em outro caminho de inserção, aquele dos jovens que buscam, por meio dos estágios, ingressar no quadro permanente da organização e, aos poucos, crescer profissionalmente. 
Para esse grupo de jovens, o marco final da inserção profissional está na efetivação em uma empresa que tenha o ambiente propício para o desenvolvimento profissional, que ocorre em etapas, passando pela estabilidade na contratação e posteriormente com o crescimento lento dentro da estrutura da empresa. Trata-se de uma forma de inserção próxima da sugerida por Vérnières (I997) que considera o ingresso no mercado de trabalho o momento em que o indivíduo alcança um emprego.

O estágio é visto como a via de acesso que possibilita o ingresso e a possibilidade de efetivação. Esse crescimento pode ou não ocorrer na grande empresa, embora encontrar uma organização de renome seja desejado pela crença de que haverá uma estrutura organizada de crescimento interno, um plano de carreira que passe pelos diferentes níveis organizacionais.

Esses estudantes têm um perfil mais conservador, pois buscam atrelar sua carreira ao crescimento na organização. Seus objetivos de carreira são de longo prazo, e cada etapa (estágio, contratação) é explorada para obter o maior aprendizado possível. Como os estudantes do grupo anterior, também buscam grandes processos seletivos, no entanto reconhecem que estes nem sempre representam uma boa oportunidade, sendo importante avaliar a vaga disponível e a empresa para ver se estas estão de acordo com seus valores e suas expectativas de crescimento pela via do estágio por meio de indicação ou encaminhamento dos centros de integração.

\section{$5=3.30$ empreendedorismo}

Os caminhos que se constroem a partir da experiência de estágio nem sempre conduzem à grande empresa. Alguns estudantes veem nesse período o momento de adquirir conhecimentos práticos para futuramente abrir seu próprio negócio. Para aqueles que encontraram sua vocação empreendedora no curso da inserção profissional, esta nasceu ligada à vontade de maior liberdade na forma de gestão ou como um caminho de ascensão mais rápida para um posto de gestor. Os estágios representam um meio de teste e aprendizado que lhes permite conhecer o meio organizacional.

Foi durante meu estágio na Comunication, na verdade já tinha um pouco uma semente da época da PS [empresa júnior], a gente lidava com pessoas empreendedoras. Tinha muitos empreendedores que tinham seu negócio e a gente conhecia a história de vida. Achava legal me identificar com aquilo. Durante o estágio da Comunication, quebrar aquela visão. Isto aqui é muito chato. Era completamente diferente do que eu imaginava que iria ser, eu achei que iria gostar e eu não aguentava ficar. 
Não pela empresa em si. No início começou com uma indignação com a empresa, como as coisas funcionavam, achava tudo muito devagar. Para tu conseguir qualquer coisa, iria levar no mínimo 25 anos porque é a cultura da casa, não que eles estejam errados, mas era uma coisa que era o contrário daquilo que eu queria, porque eu queria uma coisa mais dinâmica e, a partir daquilo, eu comecei a pesquisar outras coisas e começou a surgir o interesse de montar uma empresa e foi até conversando com este meu colega. "Bah! Estou de saco cheio, o que eu queria era montar alguma coisa” e tal. E a partir daí, cada dia que passava, muitos dias até eram difíceis de estar indo lá trabalhar porque a ideia era estar fora. [...] Mas foi nesse momento e a partir disso foi só desenvolvendo todas as minhas outras experiências, a minha visão é pegar aquilo e já imaginar alguma coisa para mim (Wilson, 22 anos).

Para esses estudantes, o processo de inserção termina quando conseguem abrir o próprio negócio, e, para isso, estabelecem metas individuais e etapas para que possam alcançar o objetivo. Reconhecem que a abertura de uma empresa não é algo fácil, que demanda muito empenho e preparo para assumir responsabilidades mais sérias. Seus espaços profissional e pessoal estarão muito próximos, e obter bons resultados na empresa relaciona-se com os resultados profissionais e com o desenvolvimento da carreira.

Para tanto, é preciso um investimento anterior, passar por etapas, como sugere um dos entrevistados - estágio, emprego formal, estabilidade - e então buscar abrir seu negócio. Wilson, um dos entrevistados, é mais ousado e, apesar de ter possibilidade de crescimento profissional no banco em que estagia, essa não é uma possibilidade que o atraia. Para ele, o empreendedorismo possibilita liberdade e ascensão rápida como gestor.

Para o estudante que pretende seguir o caminho do empreendedorismo, o estágio é um meio de aprender sobre a vivência organizacional, de adquirir experiência para futuramente utilizar em sua própria empresa. Assim, busca uma maior variedade de experiências e sabe que estas têm um caráter temporário. Diferentemente dos estudantes do modelo anterior, não almeja efetivar-se na organização, mas aprendizado ou recursos para investir em seu próprio negócio.

\subsubsection{0 serviço público}

O estágio é tratado como um período de formação e de inserção mesmo para os estudantes que se preparam para seleções que nem sempre consideram experiência prévia, como é o caso da maior parte dos concursos públicos. Para esses estudantes, os estágios possibilitam certa estabilidade durante o curso, enquanto se preparam para os concursos que lhes interessam. 
É que eu vejo que é um lugar em que eu posso ir estudar e crescer. Vejo o serviço público, a pessoa que está lá reclamar, ah meu salário está ruim. O serviço público te dá a oportunidade de estudar, ou seja, tu não quer, teu salário está ruim, tu não deve reclamar, o serviço público te propicia a oportunidade de estudar [...] (Evandro, 25 anos).

Evandro, assim como outros estudantes, encontrou um emprego numa organização, mas espera passar em um concurso e ingressar na função pública.

Neste estudo, não se pretende estabelecer um perfil a fim de evitar uma postura determinista, no entanto chama a atenção que, nesse grupo, estavam principalmente estudantes do gênero feminino ou oriundos de escolas públicas. Embora não seja decisivo, o pertencimento a esses grupos parece ser um elemento que contribui para a escolha da função pública, evidenciando que elementos adscritos e do meio de origem influenciam nas escolhas profissionais futuras. Outros estudantes, além das condições anteriormente descritas, são filhos de funcionários públicos e espelharam-se nas experiências dos pais para essa escolha.

Além da maior segurança oferecida pelo trabalho no setor público, foi destacado também o grande espaço de trabalho que existe nos órgãos governamentais, que precisam do administrador para a melhoria de processos e das formas de gestão, ou seja, é um espaço que oferece grandes desafios e que carece da atenção e empenho de administradores, assim como o setor privado.

Além disso, é visto como uma carreira, um caminho que permite manter-se atualizado realizando cursos de especialização e mestrado, diferentemente da iniciativa privada, em que a competitividade e a exigência requerida no trabalho não propiciam espaço que facilite a continuidade da formação. O setor público por algum tempo foi visto como um espaço burocrático, sem grande espaço para desenvolvimento e desafios profissionais. No entanto, nos últimos anos, tem se tornado mais atrativo, com altos salários e possibilidades de desenvolvimento profissional e qualificação. Para esses estudantes, tanto o período de estágios quanto a possível efetivação representam um momento de busca de recursos para sobreviver, enquanto se preparam para prestar concurso. Analogamente, essa inserção se assemelha àquela do estudante que busca um posto como gestor na grande empresa. Embora o cargo que postule possa ser de nível técnico e não gerencial, há um objetivo reconhecido como ponto final do período de inserção.

Para outros, o emprego público é uma forma de adquirir recursos e suprir carências de formação, garantindo o pagamento de cursos de informática e idiomas para conquistar melhores oportunidades no futuro. 
A minha ideia é acabar a faculdade agora e ano que vem tentar concurso. Só concurso, pagar um curso e só concurso, só concurso. E se pintar, fazer uma pós. [...] Porque eu preciso estabilidade, preciso trabalhar com carteira assinada. Eu preciso ... eu quero fazer muita coisa, não é que eu vá passar num concurso e passar a vida toda naquele cargo, mas eu preciso ter um emprego. Onde eu vou ter uma melhor remuneração e uma chance de ter uma perspectiva de vida. Nem que eu junte dez anos. Eu tenho muitas ideias, eu já tenho um planejamento de cinco, seis anos da minha vida (Lisandro, 22 anos).

Para alguns desses jovens, o serviço público surge como um espaço que possibilita formação e aprimoramento profissionais. Embora os concursos para ingresso no setor público sejam considerados difíceis, demandando bastante empenho e estudo, a iniciativa privada é considerada ainda mais exigente, requerendo um perfil específico com competências além daquelas que eles conseguem por meio da formação universitária. Assim, o ingresso no emprego público seria um meio de se aprimorar e, em alguns casos, de adquirir a qualificação que acreditam necessária para que possam se candidatar a emprego no setor privado.

\subsubsection{0 caminho da pesquisa na universidade}

Nesse percurso, a universidade é reconhecida tanto como espaço de formação como meio de desenvolvimento de carreira. Para os estudantes, o estágio representa um período de confirmação de que o caminho na grande empresa não corresponde às suas expectativas.

Três entrevistados optaram por seguir a carreira universitária, iniciando o mestrado logo ao término dos estudos de graduação. O caminho à formação de pós-graduação stricto sensu surge sob duas possibilidades: uma forma de eles ampliarem o período de estudos enquanto não tenham claramente definidos os seus objetivos profissionais ou como um caminho alternativo ao da empresa, em que a relação com esta se manterá como observadores por meio do ensino e da pesquisa.

[...] o gerente, diretores e diretores maiores [...] os caras tão sempre viajando, eu chego às 8 da manhã, os caras já tão aqui, eu saio às 6 da tarde, os caras continuam até de noite. [...] Sim, o cara nem para em casa!! Eu me lembro uma vez em que veio o vice-presidente de RH dos EUA e teve uma janta, que era paga pela empresa. Tava um diretor nosso e todo pessoal do RH. [...] Logo no início, tocou o celular do vice-presidente de $\mathrm{RH}$, e ele, a partir daquele momento, até o final da janta, 
ficou num canto do restaurante pra poder falar direito. O restaurante tava vazio, tava tranquilo, não teve problema, então ele ficou assim, mais de uma hora, preso no telefone. A mesma coisa começou a acontecer com o nosso diretor e outros gerentes: às vezes saíam, mas rápido voltavam. Aí eu pensava “Ah, mas eu não quero isso aî”, os caras não podem sair pra jantar, não têm tempo pra familia (Vagner, 24 anos).

No caso de Vagner, observa-se a segunda situação: num primeiro momento, traçou planos semelhantes aos da maior parte de seus colegas, no entanto a experiência de estágio na grande empresa o fez rever seus objetivos e dar um novo direcionamento à sua vida.

Nesse caso, o estágio serviu como um período de teste no qual identificou que não gostaria de construir carreira e ter uma vida no ritmo requerido pelas grandes corporações. Vagner também ressalta a importância dos valores do trabalho recebidos de sua família, que considera importante, mas não pode ser um espaço prioritário e que interfira nas demais esferas de vida.

De modo geral, os estudantes desse grupo já têm desde o ingresso na universidade a ideia de experimentação e das possibilidades que podem conhecer por meio dos estágios. A carreira acadêmica aparece como um estranhamento para grande parte dos alunos de Administração, visto que é um curso voltado para a formação da prática organizacional. Para eles, trata-se de uma possibilidade a ser testada. São alunos que buscam refletir e explorar os diferentes caminhos de inserção até escolherem aquele que querem seguir.

\section{ESTÁGIOS: CONSTRUÇÃO DE CARREIRA, DESAFIOS E PREPARAÇÃO PROFISSIONAL}

Após a apresentação dos percursos de inserção dos jovens estudantes de Administração, reafirma-se que o estágio representa um caminho institucionalizado (além da formalização legal e das instituições de ensino, é reconhecido por empresas e estudantes) a ser seguido para ingressar no mercado de trabalho. Apesar do caráter de formação, o estágio nem sempre representa a etapa inicial do processo de inserção profissional. Pelas entrevistas, verifica-se que a primeira experiência profissional dos estudantes pode não estar relacionada com o curso de formação e normalmente se vincula à busca pelo conhecimento do mundo do trabalho ou à independência financeira.

Os elementos institucionais dão a moldura que define o início do processo de inserção profissional. As normas de instituições de ensino, os agentes inte- 
gradores e as políticas de recursos humanos das empresas organizam o processo de entrada e de reconhecimento do mercado de trabalho. No entanto, depois de reconhecidas a estrutura do mercado e as possibilidades que este oferece, os aspectos individuais, como a trajetória particular e as expectativas com relação ao trabalho, passam a direcionar o percurso de inserção. Essa articulação entre aspectos individuais e institucionais vai ao encontro do conceito de inserção profissional de Dubar (200I), que destaca a relevância de elementos do contexto em conjunto com as trajetórias individuais.

Os estágios tornam-se centrais no segundo momento, quando o jovem procura experiência profissional relacionada à sua área de formação, quando busca testar seus conhecimentos e aptidões diretamente relacionadas ao seu curso de formação. Nota-se que há dois marcos de ingresso no mercado de trabalho para os estudantes do curso de superior em Administração: o primeiro refere-se à experiência que o insere no mundo do trabalho, que muitas vezes é realizado com o auxílio dos pais, familiares ou amigos; o segundo é de construção da carreira e de aprofundamento dos possíveis caminhos futuros.

O desemprego e a concorrência que surgem em decorrência do aumento do número de alunos que ingressam no ensino superior tornam-se uma preocupação para encontrar os melhores estágios. O segundo ingresso, mesmo que tenha a colaboração dos colegas, é um momento de disputa pelos melhores postos e diferenciação daqueles que estão mais aptos.

Nesse percurso, a imagem da grande empresa multinacional assume um importante papel. De acordo com Santos (1987), com a revolução técnico-científica, as grandes empresas que dominam os processos de inovação e criação de produtos tornam-se atores centrais na organização dos mercados nacionais e internacionais. Tal influência atinge o processo de inserção profissional, visto que, num primeiro momento, a construção da carreira na grande empresa, rumo a um posto elevado, surge como um modelo praticamente hegemônico no imaginário dos estudantes. No entanto, alguns estudantes, por meio da experiência de estágio, se dão conta que este não é o percurso que pretendem seguir. A partir da confirmação ou negação de suas expectativas na grande empresa, os estudantes se direcionam para diferentes caminhos, em que o estágio assume função importante.

Seja na confirmação ou no redirecionamento, o estágio é importante no processo de inserção profissional dos jovens estudantes de Administração. Constitui um primeiro momento no qual há maior flexibilidade e tolerância para erros e correções de trajetória, além de um nível moderado de concorrência, se comparado àquela que vão encontrar após a conclusão do curso.

Para aqueles que obtiveram a confirmação da carreira desejada, o estágio é o meio de acesso às empresas, caminho pelo qual podem mostrar seu conhecimento e suas competências, o que pode resultar, posteriormente, em efetiva contratação. Para aqueles que não pretendem vínculos com a empresa, é um 
período de espera e preparação, em que estudam ou adquirem conhecimento e experiência, sobretudo em grandes empresas, enriquecendo o currículo, que se torna uma credencial de destaque que permite ao estudante postular vagas mais valorizadas, que normalmente estão vinculadas aos programas de trainee, em que acreditam que terão um desenvolvimento mais acelerado na empresa.

Os que pretendem seguir pelo empreendedorismo, na função pública ou na universidade (via ensino e pesquisa), o estágio é o momento em que se certificam de que não pretendem atuar nas empresas, sobretudo a partir da experiência do estágio nas grandes corporações. No entanto, para cada carreira, os estudantes têm uma forma de utilizar a experiência de estágio. Para os futuros empreendedores, é o momento de aprender sobre as diferentes áreas da Administração para que futuramente possam agregar esses conhecimentos no desenvolvimento de suas próprias empresas. Para os que pretendem seguir na função pública, é um período moratório em que estudam e se preparam para a prestação de concursos; em alguns casos, chegam a ser efetivados, mas esperam a segurança do emprego público para que possam se desenvolver com maior segurança. Aqueles que se direcionam para a academia têm no estágio um momento de negação do vínculo com as empresas e buscam na universidade preparar-se para a continuação dos estudos no mestrado tão logo concluam a graduação.

No que ser refere à inserção profissional, nota-se que o conceito deve envolver também aspectos relacionados às expectativas individuais, pois, para muitos estudantes, embora o estágio seja o caminho para uma vaga efetiva, esse momento não é considerado o final do processo de inserção. O processo se encerra quando o jovem encontra um posto de acordo com suas expectativas, que, por sua vez, são influenciadas e alteradas por sua origem familiar, formação e experiências profissionais.

Embora se tenha um estudo preliminar, nota-se que o conceito de inserção profissional é importante para compreender a dinâmica de estrutura do mercado de trabalho de cada profissão e região. Assim, sugere-se que outros estudos sejam realizados em diferentes cursos de formação e outras regiões, a fim de confirmar os aspectos que são característicos do mercado de trabalho do país e aqueles que são particulares de cada profissão ou região.

Apesar de o caráter de aprendizado ser predominante nos estágios, diversos elementos (requisitos, forma de seleção, atividades realizadas, responsabilidades delegadas para os estudantes etc.) confirmam que este tem sido cada vez mais próximo de uma relação trabalhista. Isso é consequência do modelo de estágio não obrigatório institucionalizado no Brasil, no qual predomina a distância entre empresas e universidades e de contratos de duração mais longa, aproximando-se de uma relação de trabalho por tempo determinado. Se, num primeiro momento, essa prática contribui para a redução de custos e a manutenção de um trabalhador qualificado na empresa, a continuidade dessa prática pode contribuir para 
o desenvolvimento de um padrão de inserção, em que predominam o nomadismo e a falta de comprometimento com a organização.

Assim, por um lado, os estágios representam um meio de acesso facilitado dos estudantes ao mundo do trabalho, contribuindo para o processo de inserção. Por outro, a ampliação do número e da duração dos estágios realizados antes de conquistarem um posto formal evidencia a ampliação do período de transição para a esfera laboral, que pode, por vezes, passar por vínculos precários.

Em ambos os casos, os estágios constituem uma pré-carreira, um período de socialização no mundo do trabalho e de aquisição de experiência para conseguir um emprego. No caso dos estudantes de Administração, o período de estágio é obrigatório para postular vagas futuras, já que é por meio dele que inicia a construção do currículo profissional, que se tornou a credencial necessária para conseguir um emprego, confirmando que o diploma (ou, no caso dos estudantes, o período do curso em que se encontram) é apenas um requisito para que possam se candidatar às vagas. No entanto, nos processos seletivos, mais do que a formação, são valorizadas as competências adquiridas na prática.

A diversidade de caminhos decorrente dos estágios traz uma nova complexidade para a compreensão do conceito de inserção profissional. Os resultados mostram que não há uma possibilidade única e generalista para compreensão desse processo. Além disso, por estar pautado pelas expectativas individuais, devem ser consideradas as diversas trajetórias possíveis, inclusive dentro de um mesmo grupo juvenil. Também deve ser considerada a participação ativa dos demais atores que contribuem para a institucionalização desse processo e o estabelecimento de diferenças na passagem da universidade para o mercado de trabalho.

Assim, este trabalho contribui para enriquecer e tornar mais complexa a compreensão da inserção profissional, contrariando a ideia de que há um único processo de passagem em cada geração. Os processos de inserção são diversos inclusive dentro de um mesmo grupo juvenil e vinculam-se aos seus valores familiares sobre o trabalho, formação, expectativas profissionais e experiências na prática de estágios.

\section{AN ANALYSIS OF THE PROFESSIONAL INTEGRATION OF MANAGEMENT STUDENTS IN BRAZIL}

\section{ABSTRACT}

Internships are a form of "organized professional integration", structured at the interface between the educational and productive systems, where the school/ 
university incorporates practical learning aspects within its educational program in order to prepare the socialization for work. In order to understand how these transformations are reflected in the process of joining the labor world, this study aims to analyze the professional integration of Management students into the labor market starting from their experiences as interns in Porto Alegre. A constructivist approach was adopted in the study. Interviews were held with 32 students from undergraduate courses in Management who reported their experience as interns and highlighting the implications for their professional integration and expectations for a future career. It can be seen from the analysis that, despite their educational characteristics, internships do not always represent the first step towards professional integration, since the interviews reveal that the students' first professional experience is not always related to their graduate course and is normally linked to the search for knowledge of the world of the labor or financial independence from the parents. Internships become of central importance, when the young people seek for professional experience related to their educational area. At this point, individual expectations have a notable influence, since in an institutionalized form of integration and within the same group young people various possible paths need to be taken into consideration. It can be seen that there is no single and generalist way of understanding this process, since a number of paths open up as a result of the internship experience, making the concept of professional integration even more difficult to comprehend.

\section{KEYWORDS}

Professional integration; Internship; Management; Labor market; Young adults.

\section{UN ANÁLISIS SOBRE LA INSERCIÓN PROFESIONAL DE ESTUDIANTES DE ADMINISTRACIÓN EN BRASIL}

\section{RESUMEN}

Se cree que actualmente las prácticas configuren una forma de "inserción profesional organizada", estructurada en la convergencia de los sistemas educativo y productivo, en donde la escuela/universidad ya incorpora a la formación aspectos de aprendizaje práctico. Para comprender como estas transformaciones han sido reflejadas en el proceso de ingreso en el mercado de trabajo, este estudio tiene por objetivo analizar la inserción profesional de los estudiantes de administración a partir de la experiencia de las prácticas. La investigación ha utilizado 
una orientación constructivista. Han sido hechas entrevistas con 32 estudiantes de los cursos de licenciatura en Administración que han relatado sus experiencias de prácticas, apuntando sus implicaciones para la inserción profesional y sus expectativas de carrera futura. En el análisis se percibe que, a pesar del carácter de formación, las prácticas ni siempre representan la etapa inicial del proceso de inserción profesional, pues a partir de las entrevistas se verifica que la primera experiencia profesional de los estudiantes ni siempre está relacionada con el curso de formación y normalmente se vincula a la búsqueda por el conocimiento del mundo del trabajo o de la independencia financiera de los padres. Las prácticas se convierten en centrales cuando el joven busca experiencia profesional relacionada a su área de formación. En este momento, se percibe la influencia de las expectativas individuales, pues en una forma institucionalizada de inserción y dentro de un mismo grupo juvenil deben ser consideradas las diversas trayectorias posibles. Se percibe que no hay posibilidad única y generalista para la comprensión de este proceso, pues una diversidad de caminos se origina a partir de la experiencia de las prácticas, convirtiendo la comprensión del concepto de inserción profesional en algo aún más complejo.

\section{PALABRAS CLAVE}

Inserción profesional; Prácticas; Administración; Mercado de trabajo; Jovenes.

\section{REFERÊNCIAS}

AMORIM, T. G. F. Ter estagiários de Administração: bom só para as empresas? In: ENANGRAD, 4., I995, Natal. Anais... Natal: Angrad, I995.

ASSOCIAÇÃO BRASILEIRA DE ESTÁGIOS. Mapa do estágio no Brasil. 2009. Disponível em: $<$ http://www.abres.org.br/voI/stats/>. Acesso em: I2 dez. 20 Iо.

BERTERO, C. O. Ensino e pesquisa em administração. São Paulo: Thompson, 2007.

BOURDIEU, P. La misère du monde. Paris: Seuil, I983.

BRASIL. Lei n II.788, de 25 de setembro de 2008. Da definição, classificação e relações de estágio. Diário Oficial da República Federativa do Brasil, cap. I, art. Iº, Brasília, DF, 26 set. 2008.

CHARLOT, B.; GLASMAN, D. (Dir.). Les jeunes, l'insertion, l'emploi. Paris: PUF, I998.

DOMINGO, P. Logiques d'usages des stages sous statut scolaire. Formation Emploi, n. 79, p. 67-8I, 74 juil./sept. 2002.

DUBAR, C. La socialisation. Construction des identités sociales et professionnelles. Paris: Armand Colin, I99I.

$200 I$.

. La construction sociale de l'insertion professionnelle. Education et Sociétés, v. 7, n. I, p. 23-36. 
GALLAND, O. Un nouvel âge de la vie. Revue Française de Sociologie, v. XXXI, n. 4, p. 529-550, I990. Entrer dans la vie adulte: des étapes toujours plus tardives, mais resserrées. Economie et statistique, n. 337-338, p. 13-36, 2000.

. Adolescence, post-adolescence, jeunesse: retour sur quelques interprétations, Revue Française de Sociologie, v. 42, n. 4, p. 6II-640, $200 \mathrm{I}$.

Sociologie de la jeunesse. Paris: A. Colin, 2007.

GUIMARÃES, N. A. Empresariando o trabalho: os agentes econômicos da intermediação de empregos, esses ilustres desconhecidos. Dados, v. 5I, n. 2, p. 275-3II, 2008.

HASENBALG, C. A transição da escola para o trabalho. In: HASENBALG, C.; SILVA, N. V. Origens e destinos. Rio de Janeiro: Topbooks, 2003. p. I47-I72.

IBGE. Instituto Brasileiro de Geografia e Estatística: Censo Brasileiro 20ıо. Disponível em: $<$ http://www.ibge.gov.br>. Acesso em: I5 out. 20II.

LAHIRE, B. Homem plural. Os determinantes da ação. Petrópolis: Vozes, 2002.

LAURIS, R. P.; SILVA, T. N. Percepção dos ex-estagiários a respeito do programa Copesul de desenvolvimento de talentos. In: ENCONTRO DA ANPAD, 29., 2005, Brasília: Anpad. Brasília, 2005 .

LE MOIGNE, J.-L. Les épistemologies constructivistes. Paris: PUF, 2007.

NICOLE-DRANCOURT, C. Histoire d'un sujet et satut du sujet. In: LUROL, M. (Ed.). Les jeunes et l'emploi. Recherches pluridisciplinaires. Paris: La Documentation Française, I996. p. II3-I50.

NICOLE-DRANCOURT, C.; ROULLEAU-BERGER, L. L'insertion des jeunes en France. Paris: PUF. 2006.

PATTON, M. Q. Qualitative research \& evaluation methods. Thousand Oaks: Sage, 2002.

QUEIROZ, M. I. P. de. Relatos orais: do “indizível” ao “dizível”. In: SIMSON, O. de M. von (Org.). Experimentos com histórias de vida. São Paulo: Vértice, I988.

RITNNER, C. Estagiários e trainees. In: BOOG, G. (Coord.). Manual de T\&D. São Paulo: Makron Books, I999.

SANTOS, T. dos. Revolução científico-técnica e acumulação do capital. Petrópolis: Vozes, I987.

SPINK, M. J. P. Produção de sentidos no cotidiano: uma abordagem teórico-metodológica para análise das práticas discursivas. In: SPINK, M. J. P. (Org.). Práticas discursivas e produção de sentidos no cotidiano: aproximações teóricas e metodológicas. São Paulo: Cortez, 2004. p. 4I-6I.

SPINK, M. J. P.; FREZZA, R. M. Práticas discursivas e produção de sentidos. In: SPINK, M. J. P. (Org.). Práticas discursivas e produção de sentidos no cotidiano. São Paulo: Cortez. 2004.

TREVISAN, M.; WITTMANN, M. L. Estágios extracurriculares e a formação de administradores. In: ENANPAD, 2., 2002, Salvador. Anais... Salvador: Associação Nacional de Programas de Pósgraduação em Administração, 2002.

VÉRNIÈRES, M. L'insertion professionnelle, analyses et debats. I997.

VILLELA, L. E.; NASCIMENTO, L. M. F. do. Competências pós-industriais exigidas pelas empresas a estagiários e recém-formados: pesquisa de campo elaborada junto a sete unidades do Ciee. In: ENANPAD, 27., 2003, Atibaia: Anpad. Atibaia, 2003. 